\title{
Cryopreservation of Mulberry (Morus spp.) Germplasm
}

\section{Ahmed Abd El-Wahab El-Homosany ${ }^{1}$ and Mina Samaan Farag ${ }^{2}$}

\author{
${ }^{1}$ In vitro Storage Plant and Cryopreservation Laboratory, National Gene Bank and Genetic \\ Resources, Agricultural Research Center, Giza, Egypt \\ ${ }^{2}$ Horticulture Department, Faculty of Agriculture, Ain Shams University, Shoubra El-Khiema, Cairo, \\ Egypt.
}

Received: 10 Feb. 2020 / Accepted 15 April 2020 / Publication date: 30 April 2020

\begin{abstract}
The aim of this study is to preserve the dormant buds and shoot tips of mulberry as germplasm due to its economic, nutritional and medicinal importance. Dormant buds of white and black mulberry were collected in winter (mid-January and mid-February) from mature trees and desiccated for $24 \mathrm{hrs}$, then placed in the aluminum foils and directly plunged in liquid nitrogen (LN) for an hour. Bud burst, shoot formation and rooting percentages were measured 8 weeks after planting on a mixture of peatmoss: sand (1: 1 by volume). Shoot tips of the two cultivars were cryopreserved using plant vitrification solution $2(\mathrm{PVS} 2)$ at $0^{\circ} \mathrm{C}$ for $0,30,45$ and $60 \mathrm{~min}$ and directly plunged into $\mathrm{LN}$ or without LN treatment. Shoot regrowth percentage was determined after eight weeks on full strength MS medium with $0.5 \mathrm{mgl}^{-1} \mathrm{BA}$. Results indicated that the highest shoot formation percentage (33.33\%) was observed with dormant buds taken in mid-February. Whereas, the dormant buds taken in mid-January failed to form shoots $(00.00 \%)$. Black mulberry recorded the highest shoot formation and rooting percentages (46.66 and $83.33 \%$ respectively) when cryopreserved in mid-February. On the other hand, the highest regrowth percentages of vitrificated shoot tips were achieved after 30 or 45 min duration $\left(50.00 \%\right.$ for both durations) with $\mathrm{PVS}_{2}$ of black mulberry and after 30 min duration $(41.66 \%)$ with $\mathrm{PVS}_{2}$ of white mulberry without using liquid nitrogen in all cases.
\end{abstract}

Keywords: Germplasm, Vitrification, Cryopreservation, Mulberry.

\section{Introduction}

Mulberry (Morus spp.) is one of the economically important trees. Mulberry wood is used in handicrafts, cabinet work and a major source for making field-hockey sticks and tennis rackets (Sanchez, 2002). It is cultivated for leaf, which is used as fodder for livestock and for rearing silkworm (Bombyx mori L.), besides having several medicinal properties including antioxidant (Yen et al., 1996) and hypoglycaemial activities (Kelkar et al., 1996). Mulberry fruit is good for human fresh consumption and many commercial products such as jam, marmalade, frozen desserts, pulp, juice, paste, ice cream are made from it (Koyuncu, 2004). Also, mulberry fruit is a good medicine for dysentery, constipation and avulsed teeth (Lee et al., 2011) and it is a good source of phenolic acids and flavonoids (Arfan et al., 2012). In addition, Stewart et al., (2003) found that the mature fruit contains significant amounts of resveratrol, a strong antioxidant and putative anticancer agent.

White mulberry (Morus alba L.) and black mulberry (Morus nigra L.) are of great relevance among the species belonging to the Morus genus. White mulberry is known to possess antihyperglycemic and anti-hyperpigmentation activity (Lee et al., 2002). The root bark of the plant possesses astringent and anthelmintic properties, hypotensive activity, anti-tumour activity and antimicrobial activity and is used in treatment of cough and cold (Venkatesh and Chauhan, 2008). Traditional reports of the application of $M$. alba in treatment of atherosclerosis and diabetes were experimentally validated by Enkhmaa et al., (2005) and Shibata et al., (2007). The black mulberry trees are native to northern Africa from Egypt to Morocco and has been cultivated since ancient times throughout the Mediterranean region of Asia and Europe (Berg, 2001; Ercisli, 2004; Ercisli and Orhan, 2007; Koca et al., 2008). Black mulberry is cultivated not only for the tasteful fruits, but also for its potential pharmaceutical and cosmetic use (Chiancone et al., 2007). The fruit of black mulberry has a tonic effect on kidney energy and thus, it is used as an antiphlogistic, a

Corresponding Author: Ahmed Abd El-Wahab El-Homosany, 1In vitro Storage Plant and Cryopreservation Laboratory, National Gene Bank and Genetic Resources, Agricultural Research Center, Giza, Egypt. E-mail: a-homos2007@hotmail.com 
diuretic and an expectorant (Bown, 1995; Nomura, 1999). Black mulberry fruit is good source of several phytonutrients and contains high amounts of total phenolics, total flavonoids and ascorbic acid (Gune and Cekic, 2004; Ercisli and Orhan, 2007).

The conservation of mulberry genetic resources has become very much essential to meet the desired objectives of long term management and utilization. Cryopreservation of plant materials are stored at ultra-low temperatures in liquid nitrogen $\left(-196^{\circ} \mathrm{C}\right)$. At this temperature, cell division and metabolic activities remain suspended and the material remains unchanged for a long period. Thus, cryopreservation ensures genetic stability of the mulberry germplasm besides requiring only limited space and protecting material from contamination. In mulberry, the most appropriate material for cryopreservation is the winter bud (Rao et al., 2009; Niino et al., 2011), in vitro grown shoot apices in Morus species (Gupta, 2011; Padro et al., 2012) and the explants used for cryopreservation (Yakuwa and Oka, 1988). The survival rates of winter buds stored in liquid nitrogen up to three to five years did not change significantly (Rao et al., 2009).

Plant Vitrification Solution (PVS) is an aqueous cryoprotecant solution that is non-toxic at appropriate concentrations, readily miscible with water, and a low molecular weight substance with the ability to penetrate cells rapidly. Cryopreservation based on vitrification has been widely used for preserving mulberry germplasm as nearly 908 mulberry germplasm accessions have been used for cryopreservation in India (Rao et al., 2007; 2009). In the year 2004, about 875 germplasm accessions of mulberry have been preserved in the genebank project in Japan (Kazutoshi et al., 2004).

The main objective of this study is to evaluate the cryopreservation dormant buds of white and black mulberry and shoot tips using vitrification technique with or without liquid nitrogen as means of genetic resources preservation.

\section{Materials and Methods}

\section{Cryopreservation of dormant buds}

One year old branches (twigs) of mulberry (Morus alba. and M. nigra.) with about $15-20 \mathrm{~cm}$ in length were collected in winter (mid-January and mid-February, 2019) from adult trees grown in the experimental farm of the Agricultural Research Center, Giza, Egypt.

The twigs were immediately transferred to the laboratory then divided into two groups; the first one included the twigs after dividing them into smaller units each one was a bud piece about $1-1.5 \mathrm{~cm}$ in length contains one bud. While the second group consisted of the twigs as hard wood cuttings about $15-20 \mathrm{~cm}$ in length.

The plant materials of the two groups were put on a paper at room temperature for $24 \mathrm{hrs}$ in order to reduce the moisture content in the plant tissues. Afterwards; the plant materials were placed in aluminum foil and directly plunged in Liquid Nitrogen (LN) for an hour. Cryopreserved materials were slow thawed at room temperature for 5 minutes. Each group of twigs was involved in a separate experiment.

\section{The first experiment}

Cryopreserved dormant buds excised from twigs in small pieces $(1-1.5 \mathrm{~cm})$ were washed using running tap water for one hour with adding Dettol (Chloroxylenol) then sterilized inside laminar flow hood conditions with $70 \%$ ethanol for 1 minute followed by $1 \%$ sodium hypochlorite solution was prepared using commercial bleach "Clorox" for 15 minutes before rinsing three times with sterile distilled water, 5 minutes for each. The sterilized bud pieces were cultured on basal MS medium (Murashige and Skoog, 1962) supplemented with $1.0 \mathrm{mgl}^{-1}$ Benzyl Adenine (BA), 3\% sucrose (w/v) and solidified with $0.8 \%$ agar. The cultures were maintained at temperatures $25 \pm 2{ }^{\circ} \mathrm{C}$ in dark for seven days then transferred gradually within three days to photoperiods of 16 hour day and 8 hour night supplied by fluorescent cool white lamps to provide light intensity of 3000 lux.

Survival percentage and shoot formation percentages was recorded after culture on the medium after 8 weeks. The experiment consisted of three replicates (10 buds for each replicate).

\section{The second experiment}

The cryopreserved cuttings bases were treated with Indole Butyric Acid (IBA) at concentration of 3000 ppm for 2 minutes and planted into a mixture of peatmoss: sand (1: 1 by volume) in pots then 
covered with plastic bags before be incubated in growth chamber at $25 \pm 2{ }^{\circ} \mathrm{C}$ and photoperiods of 16 hours day and 8 hours night supplied by fluorescent white lamps provide light intensity of 3000 lux for 8 weeks. The percentages of bud burst, shoot formation and rooting were recorded.

\section{Cryopreservation of shoot tips by vitrification technique}

Shoot tips were excised in April of same season shoots (10 - $15 \mathrm{~cm}$ long) and washed using running tap water for one hour, then sterilized inside laminar flow hood conditions. Then the shoot tips were sterilized with $70 \%$ ethanol for 1 minute followed by $0.5 \%$ sodium hypochlorite solution which prepared using commercial bleach "Clorox" for $10 \mathrm{~min}$. Shoot tips with three to five tiny primordial leaves were used.

The excised shoot tips 2-3 mm long were precultured on MS medium with $0.2 \mathrm{M}$ sucrose and incubated 1 day in the dark at $25^{\circ} \mathrm{C}$ then loaded with $1 / 2 \mathrm{MS}+2 \mathrm{M}$ glycerol $+0.4 \mathrm{M}$ sucrose for $20 \mathrm{~min}$ at $25^{\circ} \mathrm{C}$ before being dehydrated with a highly concentrated Plant Vitrification Solution 2 (PVS2) which composed of MS medium supplemented with $30 \%$ (w/v) glycerol, $15 \%(\mathrm{w} / \mathrm{v})$ ethylene glycol, $15 \%(\mathrm{w} / \mathrm{v}) \mathrm{DMSO}$, and $0.4 \mathrm{M}$ sucrose and $\mathrm{pH}$ was adjusted at 5.8 according to Sakai et al. (1990). Shoot tips were dehydrated with $\mathrm{PVS}_{2}$ at $0^{\circ} \mathrm{C}$ for $0,30,45$ and 60 minutes. Then replaced with $0.6 \mathrm{ml}$ of fresh chilled $\mathrm{PVS}_{2}$ solution and the cryotubes were directly plunged into LN. After at least one hour, shoot tips were rapidly thawed at $40^{\circ} \mathrm{C}$ (two minutes), after which $\mathrm{PVS}_{2}$ was drained from the cryotubes and replaced with unloading solution of liquid MS medium containing 1.2 M sucrose (Sakai et al., 1991) at $25^{\circ} \mathrm{C}$ for $20 \mathrm{~min}$. and finally they were cultured into petri dishes containing $15 \mathrm{ml}$ of recovery medium containing full strength MS medium supplemented with $30 \mathrm{gl}^{-1}$ sucrose, $7 \mathrm{gl}^{-1}$ Bacto-Agar for 7 days in the dark, and then transferred onto MS supplemented with $0.5 \mathrm{mgl}^{-1}$ benzyl adenine (BA) and incubated under the light condition.

Shoot regrowth percentage was determined after eight weeks. The experiment consisted of four replicates (3 explants for each replicate).

All experiments were arranged as factorial experiment in a completely randomized design. The obtained data were statistically analyzed according to Snedecor and Cochran (1982). Duncan's Multiple Range Test as described by Duncan (1955) Least Significant Difference (LSD) at $\mathrm{p} \leq 0.05$ level of confidence was employed to compare the differences among means.

\section{Results and Discussion}

\section{Cryopreservation of dormant buds}

The cryopreserved dormant bud pieces $(1-1.5 \mathrm{~cm})$ of both cultivars (white and black mulberry) didn't survive after culturing because of the high rate of contamination appeared after 14 days of culture may due to endophytic contamination. So, there was no data were recorded for this experiment.

The obtained results were in agreement with Vijayan et al. (2011) who found that when mature nodal plants of Morus spp. were used for micropropagation, fungal growth takes place after 20-30 days from the lenticels and scale leaves. In addition, the contamination depends greatly on genotype, maturity of the explants, season and this problem associated in mulberry bud culture.

The effect of cultivar and planting date on bud burst percentage of white and black mulberry dormant buds after cryopreservation, data in Table (1) and Fig. (1) revealed that black mulberry exhibited the highest bud burst percentage $(55.00 \%)$ without significant difference in compare to white mulberry which recorded $45.00 \%$ bud burst percentage.

Table 1: Effect of cultivar and planting date on bud burst percentage of white and black mulberry dormant buds after cryopreservation.

\begin{tabular}{|c|c|c|c|c|}
\hline Cultivar & Date & Mid-January & Mid-February & Mean \\
\hline White mulberry & & $23.33 \mathrm{c}$ & $66.66 \mathrm{~b}$ & $45.00 \mathrm{~A}$ \\
\hline Black mulberry & & $30.00 \mathrm{c}$ & $80.00 \mathrm{a}$ & $55.00 \mathrm{~A}$ \\
\hline Mean & & 26.67 B & $73.33 \mathrm{~A}^{\vee}$ & \\
\hline
\end{tabular}

Means followed by the same letter (s) are not significantly different from each other at $5 \%$ level.

The highest bud burst percentage (73.33\%) was noticed with dormant buds taken in mid-February compared to dormant buds taken in mid-January $(26.67 \%)$ with significant difference between them. 
The interaction between the two studied factors showed that dormant buds of black mulberry taken in mid-February recorded the highest significant bud burst percentage $(80.00 \%)$, followed by those of white mulberry taken in the same date $(66.66 \%)$. Meanwhile, the lowest bud burst percentage $(23.33 \%)$ was recorded in dormant buds of white mulberry taken in mid-January without significant difference in compare to dormant buds of black mulberry taken in the same date (30.00\%).

The effect of cultivar and planting date on shoot formation percentage of white and black mulberry dormant buds after cryopreservation, data in Table (2) and Fig. (1) showed that black mulberry exhibited the highest shoot formation percentage significantly $(23.33 \%)$. Meanwhile, white mulberry recorded $10.00 \%$ shoot formation percentage. The highest shoot formation percentage $(33.33 \%)$ was observed with dormant buds taken in mid-February. Whereas, the dormant buds taken in mid-January failed to form any shoots $(00.00 \%)$. The interactions between the two studied variables showed that the highest significant percentage of shoot formation was in favor of black mulberry taken in mid-February $(46.66 \%)$ compared with those of white mulberry taken in the same date $(20.00 \%)$. Meanwhile, both cultivars failed to form shoots when dormant buds taken in midJanuary $(00.00 \%)$.

Table 2: Effect of cultivar and planting date on shoot formation percentage of white and black mulberry dormant buds after cryopreservation.

\begin{tabular}{|c|c|c|c|c|}
\hline Cultivar & Date & Mid-January & Mid-February & Mean \\
\hline White mulberry & & $00.00 \mathrm{c}$ & $20.00 \mathrm{~b}$ & $10.00 \mathrm{~B}$ \\
\hline Black mulberry & & $00.00 \mathrm{c}$ & $46.66 \mathrm{a}$ & $23.33 \mathrm{~A}$ \\
\hline Mean & & 00.00 B & $33.33 \mathrm{~A}^{\circ}$ & \\
\hline
\end{tabular}

Means followed by the same letter (s) are not significantly different from each other at $5 \%$ level.

Our results in agreement with Niino et al. (2011) who obtained survival frequency of winter buds of "Kenmochi" mulberry that had been stored for 11.5 years in LN tanks and observed $98 \%$ survival and these results confirmed that the technique of cryopreservation of mulberry dormant buds is appropriate and can be safely preserved in LN tanks. Cryopreservation of Morus alba L. was reported using winter-dormant buds by Atmakuri et al. (2009). In addition, successful cryopreservation of dormant buds is related to the cold hardy state of explants and consequently to the temperature fluctuation of the year (Towill and Ellis 2008).

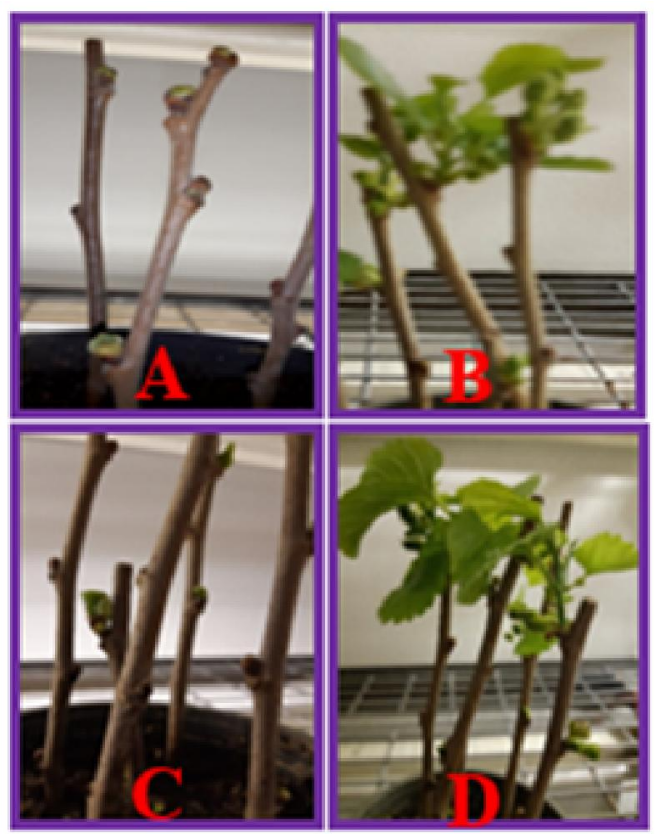

Fig 1: Cryopreserved dormant cuttings after planting in mixture of peatmoss : sand $(1: 1 \mathrm{v} / \mathrm{v})$. A and $\mathrm{B}$ bud burst and formed shoots of white mulberry respectively, $\mathrm{C}$ and $\mathrm{D}$ bud burst and formed shoots of black mulberry respectively. 
Data in Table (3) indicated that black mulberry cuttings achieved the highest rooting percentage $(83.33 \%)$ in compare to white mulberry $(70.83 \%)$ cuttings with insignificant difference between them.

The planting date insignificantly affected the rooting percentages of mulberry cuttings; despite the preference of mid-January to mid-February.

Regarding the interaction between the two studied variables; data proved that the cryopreserved black mulberry cuttings achieved the highest rooting percentages significantly in both planting dates with the same percentage ( $83.33 \%$ and $83.33 \%$ respectively) followed by those of white mulberry in mid-January $(75.00 \%)$ then the cuttings of the same cultivar in mid-February $(66.66 \%)$.

Table 3: Effect of cultivar and planting date on rooting percentage of white and black mulberry cuttings after cryopreservation.

\begin{tabular}{|c|c|c|c|c|}
\hline Cultivar & Date & Mid-January & Mid-February & Mean \\
\hline White mulberry & & $75.00 \mathrm{ab}$ & $66.66 \mathrm{~b}$ & $70.83 \mathrm{~A}$ \\
\hline Black mulberry & & $83.33 \mathrm{a}$ & $83.33 \mathrm{a}$ & 83.33 A \\
\hline Mean & & $79.17 \mathrm{~A}^{\prime}$ & $75.00 \mathrm{~A}^{\prime}$ & \\
\hline
\end{tabular}

Means followed by the same letter (s) are not significantly different from each other at $5 \%$ level.

In this concern, Kalyoncu, et al. (2009) reported that the highest rooting percentage of soft wood cuttings was determined from black mulberry in 2000 and 3000 ppm IBA doses application (100\%). On the other hand, Polat (2008) stated that most favorable rooting results were obtained from hard wood cuttings treated with 5000 ppm IBA when prepared in mid-January. The highest rooting percentage was $31.7 \%$, was obtained with $5000 \mathrm{mgl}^{-1}$ IBA in 'Beyrudi' cultivar.

\section{Cryopreservation of shoot tips by vitrification technique}

Data in Table (4) and Fig. (2) showed the effect of exposure duration to $\mathrm{PVS}_{2}$ (min.), liquid nitrogen treatment and cultivar on regrowth (\%) of white and black mulberry shoot tips.

As for to the effect of duration of $\mathrm{PVS}_{2}$ treatment (min.) results revealed that the highest shoot regrowth percentage $(35.41 \%)$ was noticed with shoot tips treated for $30 \mathrm{~min}$. PVS2 with no significant differences in compare to those of zero $\mathrm{PVS}_{2}$ and $45 \mathrm{~min}$. $\mathrm{PVS}_{2}(29.17 \%)$ without significant differences in-between. While, shoot tips treated for $60 \mathrm{~min}$. $\mathrm{PVS}_{2}$ gave the lowest shoot regrowth percentage (18.75\%) significantly compared to those of $30 \mathrm{~min}$. treatment.

Regarding the effect of liquid nitrogen treatment, data showed that shoot tips of black mulberry without liquid nitrogen treatment achieved the highest significant regrowth percentage $(52.08 \%)$ followed by those of white mulberry without liquid nitrogen $(31.25 \%)$ which not significantly differed to those of black mulberry treated with liquid nitrogen $(22.92 \%)$. Whereas, the lowest regrowth percentage was recorded by the shoot tips of white mulberry treated with liquid nitrogen (6.25\%).

With regard to the effect of interaction among the studied variables results showed that the highest regrowth percentage $(66.66 \%)$ was obtained in black mulberry shoot tips with zero duration of $\mathrm{PVS}_{2}$, without liquid nitrogen and significantly differed to all treatments, followed by those of the same cultivar which treated with $\mathrm{PVS}_{2}$ for 30 and $45 \mathrm{~min}$. (50.00 and 50.00\%) without liquid nitrogen treatments as these percentages considered the highest among the other treatments of shoot tips of black mulberry vitrificated. Shoot tips of white mulberry treated with $\mathrm{PVS}_{2}$ for $30 \mathrm{~min}$. without liquid nitrogen gave $41.66 \%$ regrowth as this percentage considered the highest one of vitrificated shoot tips of white mulberry.

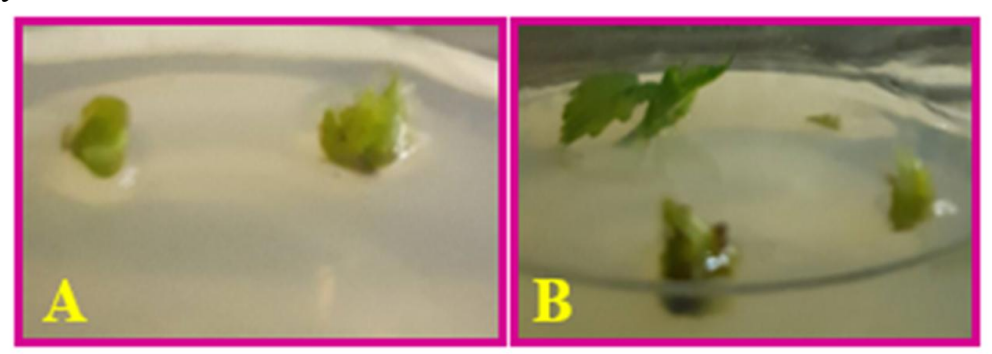

Fig. 2: Regrowth of shoot tips (A) white mulberry and (B) black mulberry after cryopreservation and vitrification with $\mathrm{PVS}_{2}$ for $30 \mathrm{~min}$. 
Table 4: Effect of exposure duration to $\mathrm{PVS}_{2}$ (min.), liquid nitrogen treatment and cultivar on regrowth $(\%)$ of white and black mulberry shoot tips.

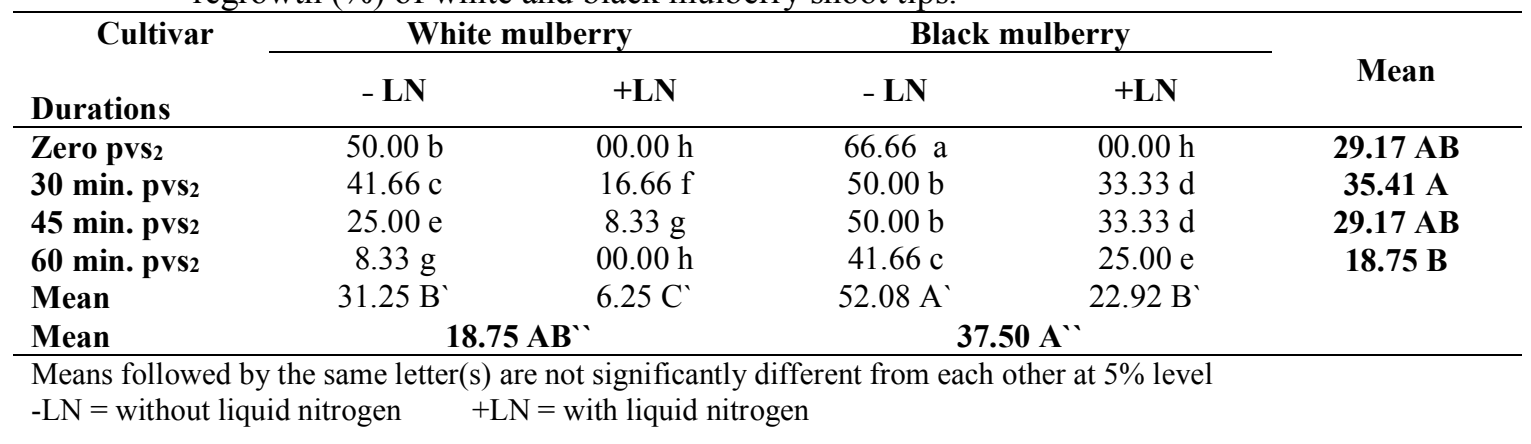

It's worthy to notice that shoot tips of white mulberry treated with zero and 60 min. durations of $\mathrm{PVS}_{2}$ with liquid nitrogen and shoot tips of black mulberry treated with zero duration of $\mathrm{PVS}_{2}$ with liquid nitrogen did not show any growth could be detected.Based on these results, the highest regrowth percentage of cryopreserved shoot tips was achieved after 30 or 45 min. dehydration with pvs $_{2}$ of black mulberry and 30 min dehydration with pvs 2 of white mulberry.

Our results went in parallel with Sakai et al. (2008) who studied the effects of the application of the vitrification protocols on cryopreservation of mulberry shoot apices and reported that regrowth after immersion in LN increased with the increasing of the duration of $\mathrm{pvs}_{2}$ treatment from 5 to 30 min. so the explants treated for $30 \mathrm{~min}$. with the standard vitrification protocol showed the highest recovery $(47 \%)$, pvs $_{2}$ treatment of $60 \mathrm{~min}$. did not further increase regrowth. Also, they pointed that the accurate control of dehydration is critical for prevention of tissue damage by chemical toxicity and strong osmotic stress during pvs $2_{2}$ treatment. On the contrary, Nino et al., (1992) reported that shoot formation of vitrified shoot tips increased considerably from 30 to $80 \mathrm{~min}$ exposure of pvs 2 and reached a maximum (70\%) at 90 min exposure of 13 cultivars of mulberry from 7 species.

\section{Conclusion}

Cryopreservation using dormant buds is an easy and simple technique that can be carried out in a laboratory with standard equipment which may facilitate its practical implementation by genebanks and it avoids possible toxic effects of chemical cryoprotectants which are required in conventional methods.

Cryopreserved dormant buds of black mulberry when taken in mid-February gave the highest bud burst percentage $(80.00 \%)$ and shoot formation percentage $(46.66 \%)$. Results obtained from our study appears to be promising for facilitating large scale cryopreservation of dormant buds in genebanks.

\section{References}

Arfan, M., R. Khan and A. Rybarczyk, 2012. Antioxidant Activity of Mulberry Fruit Extracts. Int. J. Mol. Sci., 13: 2472-2480.

Atmakuri, A.R., R. Chaudhury, S.K. Malik, S. Kumar, R. Ramachandran and S.M.H. Qadri, 2009. Mulberry biodiversity conservation through cryopreservation. In Vitro Cell Dev. Biol. Plant 45:639-649.

Berg, C.C., 2001. Moreae, Artocarpeae, and Dorstenia (Moraceae), New York Botanical Garden Press, New York, NY, USA.

Bown, D., 1995. Encyclopaedia of Herbs and Their Uses, Dorling Kindersley.

Chiancone, B., G. Patricolo and A. G. Maria, 2007. In vitro response of two Sicilian genotypes of Morus (L.) through axillary bud culture. Caryologia, 60(1-2): 178-181.

Duncan, D.B., 1955. Multiple range and multiple F tests. Biometrics. 11, 1-42.

Enkhmaa, B., K. Shiwaku, T. Katsube, K. Kitajima, E. Anuurad, M. Yamasaki and Y. Yamane 2005. Mulberry (morus alba 1.) leaves and their major flavonol quercetin 3-(6-malonylglucoside) attenuate atherosclerotic lesion development in ldl receptordeficient mice. J. Nutr., 135:729734. 
Ercisli, S., 2004. A short review of the fruit germplasm resources of Turkey. Genet. Resour. Crop Evol., 51: 419-435.

Ercisli, S. and E. Orhan, 2007. Chemical composition of white (Morus alba), red (Morus rubra) and black (Morus nigra) mulberry fruits. Food Chem., 103: 1380-1384.

Gune, M. and C. Cekic, 2004. Some chemical and physical properties of fruits of different mulberry species commonly grown in Anatolia, Turkey. Asian J. Chem., 16: 1849-1855.

Gupta, S., 2011. Cryopreservation of in vitro-grown shoot tips of Morus spp. and Pyrus cossonii Rehder by encapsulation-dehydration. Acta Hort. 908: 309-318.

Kalyoncu, I. H., N. Ersoy, M. Yilmaz and M. Aydin, 2009. Effects of humidity level and IBA dose application on the softwood top cuttings of white mulberry (Morus alba L.) and black mulberry (Morus nigra L.) types. African Journal of Biotechnology Vol. 8 (16), pp. 3754-3760

Kazutoshi, O., S. Kazuto, N. Takao and K. Makoto, 2004. Plant genetic resources in Japan: platforms and destinations to conserve and utilize plant genetic diversity. JARQ 39, 231-237.

Kelkar, S.M., V. A. Bapat, T. R. Ganapathi, G. S. Kaklij, P. S. Rao and M. R. Heble, 1996. Morus indica L. shoot cultures: detection of hypoglycemic activity. Curr. Sci., 71: 71-72.

Koca, I., N.S. Ustun, A.F. Koca and B. Karadeniz, 2008. Chemical composition, antioxidant activity, and anthocyanin profiles of purple mulberry (Morus rubra) fruits. J. Sci. Food Agr., 6: 39- 42.

Koyuncu, F., 2004. Morphological and agronomical characterization of native black mulberry (Morus nigra L.) in Sutculer, Turkey. Plant Genet. Res. Newsl., 138: 32-35.

Lee, S., S. Choi, H. Kim, J. Hwang, B. Lee, J. Gao and S. Kim, 2002. Mulberroside f isolated from the leaves of morus alba inhibits melanin biosynthesis. Biol. Pharm. Bull. 25:1045-1048.

Lee, Y., D. E. Lee, H. S. Lee, S. K. Kim, V. S. Lee, S. H. Kim and M.W. Kim, 2011. Influence of auxins, cytokinins, and nitrogen on production of rutin from callus and adventitious roots of the white mulberry tree (Morus alba L.). Plant Cell Tiss. Org. Cult. 105: 9-19.

Murashige, T. and F. Skoog, 1962. A revised medium for rapid growth and bioassays with tobacco tissue cultures. Physiology Plant. 15:473-497.

Nino, T., A. Sakai, S. Enomoto, J. Mogosi and K. Kato, 1992. Cryopreservation of in vitro-grown shoot tips of mulberry by vitrification. Cryo Letters, 13, 303-312.

Niino, T., K. Fukui, K. Shirata and I.M. Kashif, 2011. Cryopreservation of Mulberry winter buds in Japan. Acta Hort., 908: 483-488.

Nomura, T., 1999. The chemistry and biosynthesis of isoprenylated flavonoids from moraceous plants. Pure Appl. Chem., 71, (6): 1115-1118.

Padro, M.D.A., A. Frattarelli, A. Sgueglia, E. Condello, C. Damiano and E. Caboni, 2012. Cryopreservation of white mulberry (Morus alba L.) by encapsulation-dehydration and vitrification. Plant Cell Tiss. Org. Cul., 108 (1): 167-172.

Polat, A.A., 2008. Effect of indolebutyric acid on rooting of mulberry cuttings. Acta Hort. 774, pp. 351-354

Rao, A.A., R. Chaudhury, S. Kumar, D. Velu, R.P. Saraswat and C.K. Kamble, 2007. Cryopreservation of mulberry germplasm core collection and assessment of genetic stability through ISSR markers. Int. J. Ind. Entomol., 15, 23-33.

Rao, A.A., R. Chaudhury, S. Malik, S. Kumar, R. Ramachandran and S.M.H. Qadri, 2009. Mulberry biodiversity conservation through cryopreservation. In vitro Cell Develop. Biol. Plant, 45, 639649.

Sakai, A.; S. Kobayashi and I. Oiyama, 1990. Cryopreservation of nucellar cells of navel orange ( $C$. sinensis Osb. Var. brasliiensis) by vitrification. Plant Cell Rep. 9:30-33.

Sakai, A., S. Kobayashi and I. Oiyama, 1991. Survival by vitrification of nucellar cells of navel orange (C. sinensis Osb. Var. brasliiensis Tanaka) colled to $-196^{\circ} \mathrm{C}$. J. Plant Physiol. 137: 463470.

Sakai, A., D. Hirai and T. Niino, 2008. Development of PVS-based vitrification and encapsulationvitrification protocols. In: Reed B.M. (ed) Plant cryopreservation: a practical guide. Springer, USA, pp 421-426.

Sánchez, M.D., 2002. Mulberry for animal production FAO animal production and health paper 147. Rome, pp. 331. 
Shibata, Y., N. Kume; H. Arai, K. Hayashida, A. InuiHayashida, M. Minami, E. Mukai, M. Toyohara, A. Harauma and T. Murayama, 2007. Mulberry leaf aqueous fractions inhibit tnfainduced nuclear factor $\kappa \beta(\mathrm{nf}-\kappa \beta)$ activation and lectin-like oxidized ldl receptor-1 (lox-1) expression in vascular endothelial cells. Atherosclerosis, 193:20-27.

Snedecor, C.W. and W.G. Cochran, 1982. Statistical Methods. 7 Ed. The Iowa State University in Ames, Iowa, USA.

Stewart, J.R; M.C. Artime and C.A. O'Brian, 2003. Resveratrol: a candidate nutritional substance for prostate cancer prevention. J. Nutr., 133.

Towill, L.E. and D.D. Ellis, 2008. Cryopreservation of dormant buds. In: Reed B.M. (ed) Plant cryopreservation: a practical guide. Springer, USA, pp 421-426.

Venkatesh, K.R. and S. Chauhan, 2008. Mulberry: Life enhancer. J. Med. Plant Res. 2:271-278.

Vijayan, K.; A. Tikader and A.J.T. Da Silva, 2011. Application of tissue culture techniques for propagation and crop improvement in mulberry (Morus spp.). Tree Forest Sci. Biotech. 5: 1-13.

Yakuwa, H. and S. Oka, 1988. Plant regeneration through meristem culture from vegetative buds of mulberry (Mours bombycis Koidz) stored in liquid nitrogen. Ann. Bot., 62, 79-82.

Yen, G.C., S.C. Wu and P.D. Duh, 1996. Extraction and identification of antioxidant components from the leaves of mulberry (Morus alba L.). J. Agric. Food Chem. 44: 1687-1690. 